\title{
NEUROANATOMICAL AND FUNCTIONAL CHARACTERIZATION OF CRF NEURONS OF THE AMYGDALA USING A NOVEL TRANSGENIC MOUSE MODEL
}

\author{
P. N. DE FRANCESCO, ${ }^{a \dagger}$ S. VALDIVIA, ${ }^{\text {a† }}$ A. CABRAL, ${ }^{a}$ \\ M. REYNALDO, ${ }^{a}$ J. RAINGO, ${ }^{b}$ I. SAKATA, ${ }^{c, d}$ \\ S. OSBORNE-LAWRENCE, ${ }^{\mathrm{c}, \mathrm{d}}$ J. M. ZIGMAN ${ }^{\mathrm{c}, \mathrm{d}}$ AND \\ M. PERELLÓ ${ }^{\text {a* }}$ \\ a Laboratory of Neurophysiology, Multidisciplinary Institute of Cell \\ Biology [Argentine Research Council (CONICET) and Scientific \\ Research Commission, Province of Buenos Aires (CIC-PBA)], La \\ Plata, Buenos Aires, Argentina \\ ${ }^{\mathrm{b}}$ Laboratory of Electrophysiology, Multidisciplinary Institute of \\ Cell Biology [Argentine Research Council (CONICET) and \\ Scientific Research Commission, Province of Buenos Aires \\ (CIC-PBA)], La Plata, Buenos Aires, Argentina \\ ${ }^{\mathrm{C}}$ Division of Hypothalamic Research and Division of \\ Endocrinology and Metabolism, Department of Internal \\ Medicine, University of Texas Southwestern Medical Center, Dallas, \\ TX, United States \\ ${ }^{\mathrm{d}}$ Department of Psychiatry, University of Texas Southwestern \\ Medical Center, Dallas, TX, United States
}

\begin{abstract}
The corticotropin-releasing factor (CRF)-producing neurons of the amygdala have been implicated in behavioral and physiological responses associated with fear, anxiety, stress, food intake and reward. To overcome the difficulties in identifying CRF neurons within the amygdala, a novel transgenic mouse line, in which the humanized recombinant Renilla reniformis green fluorescent protein (hrGFP) is under the control of the CRF promoter (CRFhrGFP mice), was developed. First, the CRF-hrGFP mouse model was validated and the localization of CRF neurons within the amygdala was systematically mapped. Amygdalar hrGFP-expressing neurons were located primarily in the interstitial nucleus of the posterior limb of the anterior commissure, but also present in the central amygdala. Secondly, the marker of neuronal activation c-Fos was used to explore the response of amygdalar CRF neurons in CRF-hrGFP mice under different experimental paradigms. C-Fos induction was observed in CRF neurons of CRF-hrGFP mice exposed to an acute social defeat stress event, a fasting/refeeding
\end{abstract}

${ }^{*}$ Corresponding author. Address: Laboratory of Neurophysiology, Multidisciplinary Institute of Cell Biology, Calle $526 \mathrm{~S} / \mathrm{N}$ entre 10 y 11 , PO Box 403, La Plata, Buenos Aires 1900, Argentina. Tel: +54-2214210112; fax: + 54-221-4253320.

E-mail addresses: marioperello@yahoo.com, mperello@imbice.gov. ar (M. Perelló)

Equal contribution to this work.

Abbreviations: BAC, bacterial artificial chromosome; BLA, basolateral amygdala; $\mathrm{CeA}$, central amygdala; $\mathrm{CRF}$, corticotropin-releasing factor; DAB, 3-3'-diaminobenzidine; HFD, high-fat diet; hrGFP, humanized recombinant Renilla reniformis green fluorescent protein; IPAC, interstitial nucleus of the posterior limb of the anterior commissure; LPS, lipopolysaccharide; PBS, phosphate-buffered saline; PVN, paraventricular nucleus. paradigm or lipopolysaccharide (LPS) administration. In contrast, no c-Fos induction was detected in CRF neurons of CRF-hrGFP mice exposed to restraint stress, forced swimming test, 48-h fasting, acute high-fat diet (HFD) consumption, intermittent HFD consumption, ad libitum HFD consumption, HFD withdrawal, conditioned HFD aversion, ghrelin administration or melanocortin 4 receptor agonist administration. Thus, this study fully characterizes the distribution of amygdala CRF neurons in mice and suggests that they are involved in some, but not all, stress or food intake-related behaviors recruiting the amygdala. (c) 2015 IBRO. Published by Elsevier Ltd. All rights reserved.

Key words: amygdala, CRH, food intake, stress.

\section{INTRODUCTION}

The neuropeptide corticotropin-releasing factor (CRF) plays a key role in controlling homeostatic balance (Vale et al., 1983; Carlin et al., 2006). It is well known that CRF regulates the rapid mobilization of resources and behaviors in response to stress, as well as other important central functions including food intake and autonomic nervous system activity (Vale et al., 1983; Carlin et al., 2006). CRF neurons are concentrated in the hypothalamic paraventricular nucleus (PVN), and include the hypophysiotropic CRF neurons of the hypothalamic-pituitary-adrenal (HPA) neuroendocrine axis which becomes activated in response to stress (Bale and Vale, 2004). CRF neurons are also found in extra-hypothalamic regions of the central nervous system including the cerebral cortex, basal ganglia, amygdala, thalamus, hippocampus, and spinal cord (Swanson et al., 1983). Among the extra hypothalamic sites, CRF neurons are particularly enriched in the amygdala, which is part of complex neural circuitries that regulate a variety of behavioral and autonomic responses activated when animals are exposed to stress, fear or rewarding stimuli (Gray, 1999; Baxter and Murray, 2002; Sah et al., 2003). Surprisingly, knowledge about the CRF neurons of the amygdala is rather limited due to difficulties in identifying these neurons in rodents. Furthermore, while the distribution of CRF neurons of the amygdaloid complex in the rat has been characterized quite extensively (Cassell et al., 1986; Sakanaka et al., 1986; Marchant et al., 2007), studies on the localization of these neurons in mice are few and mainly focused on the central amygdala ( $\mathrm{CeA})$ 
(Asan et al., 2005). In either case, visualization of CRF neuronal cell bodies by immunohistochemistry requires colchicine pre-treatment, which alters normal brain physiology and severely limits its study in normal conditions (Asan et al., 2005). In recent years, several efforts have been made to facilitate the identification of CRF neurons by means of transgenic mouse models (Alon et al., 2009; Martin et al., 2010; Wamsteeker Cusulin et al., 2013; Gafford et al., 2014; Itoi et al., 2014). However, these studies were mainly focused on CRF neurons of the PVN, and little information is provided about the distribution or function of these cells in the amygdaloid complex.

To overcome this issue and get insights into the CRF neurons of the amygdala, a novel transgenic reporter mouse, in which humanized recombinant Renilla reniformis green fluorescent protein (hrGFP) is under the control of the CRF promoter, was generated. The CRF-producing cells in this transgenic mouse model, named CRF-hrGFP mice, are marked by fluorescent signal and are easily identifiable. Taking advantage of this mouse model, the distribution of CRF neurons within the mouse amygdala was fully characterized. Notably, a number of experimental conditions are known to activate the amygdala and presumably involve CRFmediated responses. However, the technical difficulties for the identification of CRF neurons in a physiologically intact context have precluded the possibility to test whether the CRF neurons of the amygdala indeed participate in such circuits. To this end, the CRF-hrGFP transgenic mouse line was used to map the induction of c-Fos within the CRF neurons of the amygdala in order to explore the functional role of amygdalar CRF neurons in different experimental conditions known to activate this brain region.

\section{EXPERIMENTAL PROCEDURES}

\section{Generation of CRF-hrGFP transgenic mice}

A line of transgenic mice that express hrGFP eutopically within CRF-producing cells was generated for this study. These animals were made through the use of various ET-cloning "recombineering" technologies (Lee et al., 2001; Muyrers et al., 2001). The original CRF bacterial artificial chromosome (BAC) was purchased from BACPAC Resources Center at Children's Hospital Oakland Research Institute and was chosen based on sequence data obtained from the Celera database. This CRF BAC, named RP24-80I22, contained nearly $92.64 \mathrm{~kb}$ sequence upstream of the CRF start codon and the entire coding sequence of $\mathrm{CRF}$, ending $\sim 38.16 \mathrm{~kb}$ downstream of the CRF stop codon. The RP24-80I22 CRF BAC was transformed by electroporation into EL250 cells, which contain heat-inducible recE and recT recombinases, for homologous recombination, and arabinose-inducible Flp-recombinase, for site-specific recombination at FRT sites (Lee et al., 2001). Next, a fragment containing the coding sequence of hrGFP followed by an SV40 polyadenylation signal (derived from the phrGFP-1 vector, Stratagene, La Jolla, CA, USA) and a kanamycin resistance gene flanked by FRT sites was inserted into the RP24-80I22
CRF BAC, at the translational start site of CRF, by ET-cloning. This insertion resulted in the removal of the 564-bp of CRF's coding sequence. Finally, the kanamycin resistance gene was removed by arabinose induction of Flp-recombinase, and the hrGFP was sequenced to ensure that no mutations had been introduced. The hrGFP-modified RP24-80I22 CRF BAC was submitted to UTSW Medical Center Transgenic Core Facility for microinjection into pro-nuclei of fertilized one-cell stage embryos of C57BL/6J mice. We were successful in generating seven different potential CRF-hrGFP founder mice, of which one resulted with the expected and abundant hrGFP expression within the amygdala. The CRF-hrGFP mice used in this study were on a pure C57BL/6J genetic background. Animals were housed under a 12:12-h light/ dark cycle in a temperature-controlled environment. They were fed standard regular chow diet and had free access to water, except when indicated. Regular chow contains $2.5 \mathrm{kcal} / \mathrm{g}$ energy, of which $3.6 \mathrm{~g} \%$ are from fat. High-fat diet (HFD) contains $3.9 \mathrm{kcal} / \mathrm{g}$ energy, of which $21.1 \mathrm{~g} \%$ are from fat. Diets were provided by Gepsa Feeds (Grupo Pilar S.A., Pilar, Buenos Aires, Argentina). This study was carried out in strict accordance with the recommendations in the Guide for the Care and Use of Laboratory Animals of the National Research Council, USA, and all efforts were made to minimize suffering. All experimentation received approval from the Institutional Animal Care and Use Committee of the IMBICE.

\section{Validation of CRF-hrGFP transgenic mice}

In order to validate the transgenic mouse model, coronal brain sections of CRF-hrGFP mice were used to perform CRF immunohistochemistry. Double immunostaining was performed in brain samples from either:1-naïve CRFhrGFP mice $(n=3)$; 2-CRF-hrGFP mice intracerebroventricularly (ICV, coordinates AP: $-0.3 \mathrm{~mm}$, L: $1.0 \mathrm{~mm}$ and $\mathrm{V}:-2.3 \mathrm{~mm})$ injected with colchicine $(32 \mu \mathrm{g}$ in $4 \mu \mathrm{L})$ 72-h before sacrifice $(n=3)$; and 3-CRFhrGFP mice bilaterally injected with colchicine $(3.2 \mu \mathrm{g}$ in $0.4 \mu \mathrm{L}$ ) into the amygdala using the stereotaxic coordinates AP:-1.2 mm, L: $-2.4 \mathrm{~mm}$ and $\mathrm{V}: 4.0 \mathrm{~mm}$, $72-h$ before sacrifice $(n=3)$. Anesthetized mice were perfused with heparinized phosphate-buffered saline (PBS) and then with $4 \%$ formaldehyde in PBS. Brains were removed, post-fixed, immersed in $20 \%$ sucrose/ $1 \%$ formalin, and cut coronally at $42 \mu \mathrm{m}$ into three equal series on a sliding cryostat. Then, sections were washed, treated with blocking solution (3\% normal donkey serum and $0.25 \%$ Triton $\mathrm{X}-100$ in PBS), and incubated with a goat anti-CRF antibody (Santa Cruz, Dallas, TX, USA, No. sc-1759, lot K1104, 1:200) for two days at $4{ }^{\circ} \mathrm{C}$. Then, sections were washed and treated with Alexa-594 donkey anti-goat antibody (Molecular Probes, Life Technologies, Carlsbad, CA, USA, cat\# A11058, 1:1000) overnight. Consecutively, sections were washed, sequentially mounted on glass slides, and coverslipped with mounting media. Fluorescent images were acquired with a Nikon Eclipse 50i and a DS-Ri1 Nikon digital camera. Then, the total number of green fluorescent- and/or red fluorescent-labeled cells was quantified through the whole amygdala. 


\section{Volumetric reconstruction and neuroanatomical characterization of the distribution of hrGFP neurons within the amygdala}

In order to describe the rostro-caudal volumetric distribution of the hrGFP neurons throughout the whole amygdala, sequential coronal brain sections from a CRF-hrGFP mouse were mounted on glass slides, coverslipped with mounting media, and then microphotographed using an epifluorescence microscope to record hrGFP fluorescence in the region of the amygdala and photographed under a binocular magnifier with oblique white illumination to obtain the gross anatomy. Registration and alignment of both image sets was performed in a semi-automated fashion using Fiji (Schindelin et al., 2012) and TrakEM2 (Cardona et al., 2012). For each image pair, the position of every hrGFP-positive cell was recorded, and the main anatomical features (borders, tracts, commissures) were delineated. Using this information a 3D model of each relevant feature was constructed in Fiji with the 3D Viewer plugin and imported into Blender (http://www.blender. org/) for volumetric representation.

In an independent study, anesthetized CRF-hrGFP mice $(n=4)$ were perfused, and their brains processed as described above in order to obtain four equal series per animal. One series of each mouse was mounted and used to visualize cytoarchitecture; in this case, brain sections were stained with thionin (cat\# T7029; Sigma-Aldrich, St. Louis, MO, USA), dehydrated in an ascending alcohol series, cleared in xylene and coverslipped. Another series of each mouse was mounted, cover slipped and used to detect hrGFP fluorescence using an epifluorescence microscope, as described above. A third series of each mouse was used to detect hrGFP-immunoreactive (IR) cells; in this case, brain sections were pretreated with $1 \% \mathrm{H}_{2} \mathrm{O}_{2}$, treated with blocking solution ( $3 \%$ normal donkey serum and $0.25 \%$ Triton X-100 in PBS), and incubated with rabbit polyclonal anti-hrGFP antibody (Stratagene, La Jolla, CA, USA, cat\# 240142, 1:1000) for 2 days at $4{ }^{\circ} \mathrm{C}$. Then, sections were treated with biotinylated donkey anti-rabbit antibody (Jackson ImmunoResearch Laboratories, West Grove, PA, USA, 1:1,000) for $1 \mathrm{~h}$, and with Vectastain Elite ABC kit (Vector Laboratories, Burlingame, CA, USA) for $1 \mathrm{~h}$, according to the manufacturer's protocols. Then, visible signal was developed with 3-3'-diaminobenzidine (DAB), giving a brown precipitate. All samples were microphotographed and used for neuroanatomical characterization of the distribution of the hrGFP neurons within the amygdala. For the analysis, the amygdala was subdivided into the following regions: (1) the basolateral amygdala (BLA); (2) the interstitial nucleus of the posterior limb of the anterior commissure (IPAC), which is a brain nucleus that lies at the junction of the striato-pallidal system and the lateral bed nucleus of the stria terminalis-central amygdaloid complex; and (3) the CeA. The brain slices were analyzed in a systematic manner rostro-caudally from bregma coordinates -0.25 to $-1.81 \mathrm{~mm}$, and three levels, at bregma $-0.22,-0.58$ and $-1.46 \mathrm{~mm}$, were chosen as representative of the anterior, middle and posterior levels of the amygdala, respectively. Neuroanatomical limits were defined as described in the mouse brain atlas (Paxinos and Franklin, 2001). In order to estimate the total number of hrGFP-IR cells in the amygdala, we quantified cells containing distinct cytoplasmic light brown chromogen reaction product in one out of four complete series of coronal sections through the whole nuclei. Then, these numbers were summed and multiplied by four. The data were corrected for double counting, according to the method of Abercrombie (Abercrombie, 1946), where the ratio of the actual number of neurons to the observed number is represented by $T$ / $T+h$ where $T=$ section thickness, and $h=$ the mean diameter of the neuron. For this, hrGFP-IR cell diameter was quantified, of at least 40 cells in each brain area and experimental group, using Fiji.

\section{Experimental protocols}

In order to get insights into the role of CRF neurons of the amygdala, different cohorts of 2-3-month-old male CRFhrGFP mice weighting 20-25 g, were single housed and exposed to a series of experimental manipulations are described below. Importantly, at least two different trials were performed for each experimental paradigm.

(1) Bacterial lipopolysaccharide (LPS) treatment: On the experimental day, fresh solutions of LPS (25 $\mu \mathrm{g} /$ mouse, cat\# L-3755; Sigma-Aldrich, St. Louis, MO, USA) were prepared with sterile endotoxin-free isotonic PBS as a vehicle and intraperitoneally (i.p.) administered to CRF-hrGFP mice $(n=4)$. Control mice were i.p. injected with vehicle alone $(n=3)$. Mice were anesthetized $2 \mathrm{~h}$ after treatment and perfused. This dose of LPS was chosen based on the basis of its ability to induce the activation of the immune system and an acute sickness response including fever, suppression of locomotor activity, anorexia, among other, which has been showed by our and others' studies (Kozak et al., 1994; Perelló et al., 2011; Walker et al., 2013). Importantly, a similar dose of LPS has been shown to induce c-Fos expression in the amygdala of mice (Tarr et al., 2012; Skelly et al., 2013).

(2) Acute social defeat stress: This test is based upon the resident-intruder paradigm, in which an experimental mouse is introduced into the home cage of a different mouse for a short-time physical encounter. This test was performed using an acute version of our previously published protocol (Chuang et al., 2011). Resident mice were aggressive $\sim 1$-yearold, $\sim 50 \mathrm{~g}, \mathrm{C} 57 \mathrm{BL} / 6 \mathrm{~J}$ breeders selected for their attack latencies, of less than $30 \mathrm{~s}$, upon three consecutive screening tests. For the encounter, experimental CRF-hrGFP mice were introduced for $10 \mathrm{~min}$ in a cage where the resident mouse had been housed for 1 week. During the exposure, all defeated CRF-hrGFP mice showed signs of stress and subordination, including vocalization, flight response, and submissive posture. Following this exposure, CRF-hrGFP mice were returned to their home cages and perfused $2 \mathrm{~h}$ later $(n=5)$. 
Defeated CRF-hrGFP mice did not exhibit visible bite marks or wounds. Importantly, a similar protocol of social defeat paradigm has been shown to activate neurons of the amygdala in rats (Martinez et al., 1998).

(3) Fasting/refeeding paradigm: Individually housed mice were fasted by removing their food from the home cages at 9:00 am. After $48 \mathrm{~h}$, mice were either perfused ( $n=4$ ) or given access to food for $2 \mathrm{~h}$ and then perfused $(n=5)$. Food intake was recorded and verified to be increased in the refeeding group as compared to non-fasted mice. Importantly, this paradigm has been shown to induce c-Fos expression in the amygdala in mice (Wu et al., 2014).

(4) Acute HFD: In the morning of the experimental day, mice were exposed to HFD ad libitum $(n=5)$ and perfused after $2 \mathrm{~h}$ of food consumption, which was verified to increase compared to mice exposed to regular chow. Of note, satiated mice were exposed to HFD in the morning, at a time of the day when spontaneous food intake is minimal, and while they remained with free access to regular chow because we have recently shown that acute HFD consumption is mainly due to the palatable nature of the stimulus and recruit centers of the mesolimbic pathway including neurons of the amygdala (Valdivia et al., 2014).

(5) Intermittent HFD: In the morning, mice were given HFD ad libitum for $2 \mathrm{~h}$ during four consecutive days $(n=6)$. Their HFD intake was recorded and verified to escalate over successive days (Berner et al., 2008). Animals were perfused $2 \mathrm{~h}$ post last HFD consumption. As explained above, these experiments were performed during the morning because HFD consumption is mainly driven by hedonic aspects of eating and involves activation of the neuronal centers of the mesolimbic pathway, including the amygdala (unpublished results).

(6) HFD withdrawal: Mice were given HFD ad libitum all day for 2 weeks. Then, mice were separated into two groups: one of them was shifted to regular chow $(n=3)$ at 9:00 am and the other remained fed with HFD $(n=3)$. All mice were perfused at 9:00 am after $24 \mathrm{~h}$ of HFD withdrawal. The inclusion of this protocol in the current study was based on the fact that it has been found an activation of the amygdalar CRF system during cocaine withdrawal in cocaine-trained rats (Erb and Stewart, 1999; Zhou et al., 2003).

(7) Conditioned HFD aversion: In the mornings of the first and second days, mice were ad libitum exposed to HFD for $2 \mathrm{~h}$ and then injected with $\mathrm{LiCl}$ $(150 \mathrm{mM}, 12 \mathrm{ml} / \mathrm{kg}$, i.p., $n=6)$ or saline $(n=3)$. On the third day, mice were exposed to HFD for $2 \mathrm{~h}$ again and perfused afterward. HFD intake was significantly reduced in the LiCl-treated group as compared to the saline-treated group, indicating that $\mathrm{LiCl}$-treated mice developed conditioned aversion to HFD. A similar protocol has been shown to effectively activate c-Fos in CeA in rats (Spencer et al., 2012).

(8) Acute restraint stress: Mice were placed in a 50-ml plastic Falcon tube, which had a small hole drilled around its base to allow ventilation, and restrained for $30 \mathrm{~min}$. Then, experimental mice were returned to their home cages and perfused $1.5 \mathrm{~h}$ later $(n=3)$. Similar protocols have been shown to increase c-For expression in several regions of the brain, including the amygdala in rats (Chen and Herbert, 1995) and mice (Nomura et al., 2003).

(9) Forced cold swimming stress: Mice were individually placed during $90 \mathrm{~s}$ into polypropylene cylinders (height $25 \mathrm{~cm}$, diameter $10 \mathrm{~cm}$ ) containing $15 \mathrm{~cm}$ of water maintained at $0-2{ }^{\circ} \mathrm{C}$. Then, experimental mice were gently dried using paper towels, returned to their home cages and perfused $2 \mathrm{~h}$ later $(n=3)$. Forced swim test is a common stressor already reported to increase c-Fos in the amygdala of rats (Zhu et al., 2011; Retson et al., 2014). The present protocol is a variation of one presented elsewhere (Heinrichs and Koob, 2006).

(10) Ghrelin administration: On the morning of the experimental day, animals were ICV-injected with $4 \mu \mathrm{L}$ of acyl-ghrelin (0.6 nmol/mouse, Global Peptide, cat\# PI-G-03, $n=3$ ). Food intake was recorded during the following $2 \mathrm{~h}$ and verified to significantly rise in the ghrelin-treated group. Mice were perfused immediately afterward. ICV ghrelin administration has been shown to activate the amygdala in mice (Hansson et al., 2014).

(11) Melanocortin 4 receptor (MC4R) agonist administration: Mice were ICV-injected with the MC4R agonist RO27-3225 (4 $\mu \mathrm{g} / \mathrm{mouse}$, Sigma-Aldrich, St. Louis, MO, USA, cat\# R3905, $n=3$ ) and perfused $2 \mathrm{~h}$ after treatment. This procedure is known to produce strong c-Fos induction in the amygdaloid complex in mice (Agosti et al., 2014).

All experimental manipulations were performed in parallel to a set of control mice. Since several of these control mice were exposed to the same experimental conditions, they were grouped for the analysis as follows: (i) control group 1: mice used as control of stress paradigms (protocols 2, 8 y 9). These mice were gentle handed for $5 \mathrm{~min}$, introduced for $10 \mathrm{~min}$ in a clean cage, returned to their home cage and perfused $2 \mathrm{~h}$ later $(n=6)$. (ii) control group 2: mice used as control of feeding paradigms (protocols 4,5 y 6 ). These mice were individually housed, exposed to a pellet of regular chow inside the home cage and perfused $2 \mathrm{~h}$ later $(n=6)$. (iii) control group 3: mice used as control of ICV treatments (protocols 10 y 11). These mice, which had been stereotaxically implanted with an indwelling sterile guide cannula a week before the experiment, were ICV-injected vehicle and perfused $2 \mathrm{~h}$ later $(n=5)$. Paradigms 1,3 and 7 had each its own specific control group. 


\section{Assessment of c-Fos and hrGFP co-localization by immunohistochemistry}

Brains of mice subjected to the different experimental protocols were coronally cut into three equal series on a sliding cryostat. For c-Fos immuno-staining, sections were pretreated with $\mathrm{H}_{2} \mathrm{O}_{2}$, blocking solution, and incubated with anti-c-Fos antibody (Calbiochem/ Oncogene, San Diego, CA, USA, cat\# PC38, 1:30,000) for two days at $4{ }^{\circ} \mathrm{C}$. Then, sections were treated with biotinylated donkey anti-rabbit antibody for $1 \mathrm{~h}$, and with Vectastain Elite $A B C$ kit for $1 \mathrm{~h}$, as described above. Then, visible signal was developed with DAB/Nickel solution, giving a black/purple precipitate. Sections were sequentially mounted on glass slides, and coverslipped with mounting media. Results were visualized in a Nikon Eclipse 50i microscope and images were acquired with a Nikon DS-Ri1 digital camera. The fluorescent hrGFP signal was confined to the perikarya and dendrites, thus allowing visualization of the nucleus with or without black/purple label for c-Fos. The analysis and counting of c-Fos/hrGFP colocalization for each mouse series were performed in bregma coordinates ranging from -0.58 to $-1.70 \mathrm{~mm}$.

\section{Quantitative analysis}

Total c-Fos-IR cells were bilaterally quantified in the whole amygdala and qualitative estimates of c-Fos-IR were made by considering both signal strength and the number of labeled cells. In order to estimate total hrGFP cells positive for c-Fos, cells containing distinct nuclear black/purple precipitate in cells with obvious green signal were bilaterally quantified in one out of three complete series of coronal sections through the whole nuclei. A blinded quantitative analysis was performed independently by two observers and expressed as total hrGFP neurons with nuclei positive for c-Fos in both amygdales.

\section{Statistical analyses}

Data are expressed as the mean \pm SEM. A one-way ANOVA followed by the Dunnet test was used to compare the percentage of hrGFP neurons with nuclei positive for c-Fos from different experimental groups to its corresponding control group, as described above. In the case where there was a single condition to be tested against its control group, Student's $t$-test was employed. Significant differences were considered when $p<0.05$. Analyses were performed using GraphPad Prism 5.0.

\section{RESULTS}

\section{Validation of CRF-hrGFP mouse model}

Transgenic mice expressing hrGFP in CRF-producing cells were generated by engineering the RP24-80I22 CRF BAC such that hrGFP is driven by CRF regulatory elements (Fig. 1A). Fluorescence microscopy confirmed an abundant presence of hrGFP-expressing cells within the amygdala. In addition, hrGFP-positive cells were detected in the nucleus accumbens, the bed nucleus of the stria terminalis, the ventral pallidum, the pontine reticular nucleus, the periaqueductal gray, the lateral dorsal tegmental nucleus, and Barrington's nucleus, all of which are brain areas known to contain CRFexpressing neurons (Swanson et al., 1983). In contrast, we failed to detect hrGFP-expressing cells in the cerebral cortex, the lateral septum, the substantia innominata, the preoptic area, the zona incerta, the hippocampus, the dorsomedial hypothalamus, the raphe magnus, the peduncular pontine tegmental nucleus, the inferior colliculus, the lateral parabrachial nucleus, the reticulotegmental nucleus of the pons, the medial vestibular nucleus, the gigantocellular reticular nucleus, and the inferior olive, where the presence of scattered CRF-positive cells has been described (Alon et al., 2009). Notably, only few hrGFP-expressing cells were found in the PVN of this transgenic line (not shown). Most importantly, no hrGFP-positive cells were detected in areas where CRF gene expression has not been previously reported. To determine whether hrGFP expression in the amygdala was restricted to CRF neurons, a histochemical analysis for hrGFP fluorescence together with CRF immunostaining was performed. The hrGFP fluorescence was very strong and mainly found in neuron cell bodies, as expected, but also in the dendrites. The immuno-histochemical visualization of CRF-producing neurons in the amygdala proved to be particularly difficult: CRF-IR signal was exclusively found in fibers with no stained cells in the amygdala of naïve CRF-hrGFP mice, and CRF-IR signal was also mainly visualized in fibers with only a few faintly stained cells in the amygdala of CRF-hrGFP mice ICVpretreated with colchicine. However, intra-amygdalar pre-treatment with colchicine was successful, resulting in the immuno-histochemical visualization of CRF-producing neuronal cell bodies in the amygdala. Under this condition, CRF-IR signal was mainly confined to the perikarya and the pattern of hrGFP fluorescence was unaffected, thus allowing estimation of the degree of co-localization of both fluorescent signals in neurons (Fig. 1B-E). Nearly $100 \%$ of CRF-IR amygdalar neurons also expressed hrGFP, while the $87 \pm 12 \%$ of green fluorescent amygdalar cells also showed CRF-IR red signal.

\section{Detailed neuroanatomical characterization of hrGFP expression within the amygdala}

Next, a more detailed neuroanatomical characterization of CRF-expressing neurons within the amygdala was performed. The hrGFP-positive neurons were distributed between rostro-caudal levels -0.25 and $-1.81 \mathrm{~mm}$ from the Bregma of adult CRF-hrGFP mouse brains (Fig. 2A-C), with most (about 63\%) located in a narrower region between rostro-caudal levels -0.47 and $-1.12 \mathrm{~mm}$ from the Bregma (Fig. 2B). The hrGFPpositive cells were observable within the anterior, middle and caudal portions of the IPAC and the rostral part of the $\mathrm{CeA}$, but they were completely absent in the BLA (see below). In order to avoid quenching of the hrGFP fluorescence signal in the course of the analysis, chromogenic immunostaining against hrGFP was also performed. Thus, neuroanatomical characterization was 
A
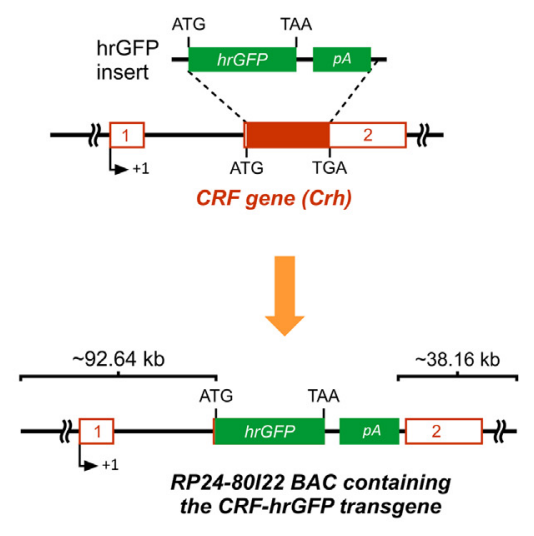

B

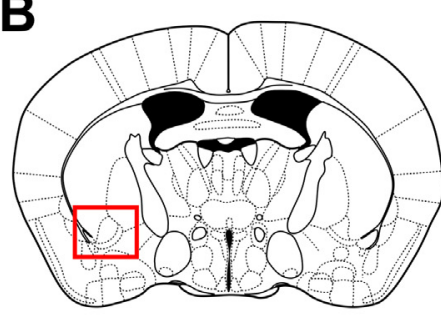

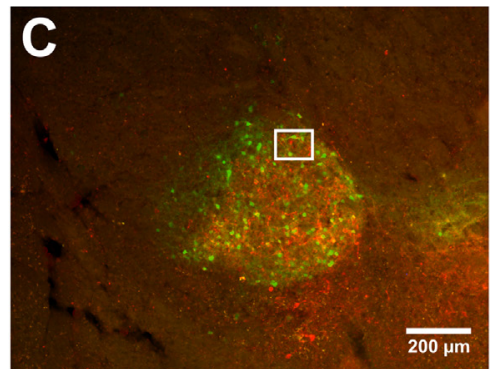
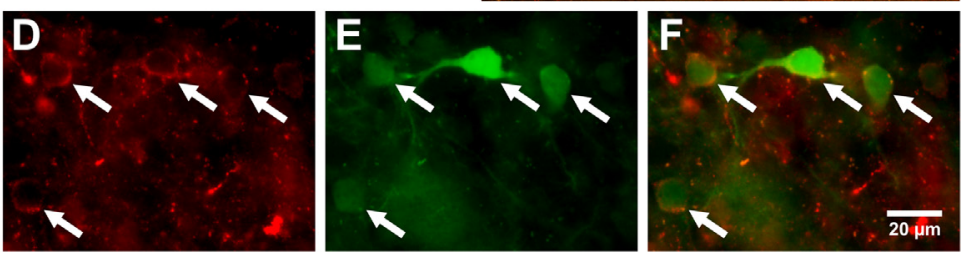

Fig. 1. Novel CRF-hrGFP mice. Panel A shows a schematic diagram of the derivation of CRF-hrGFP mice. In order to generate the transgene, the 564-bp of CRF's coding sequence (denoted by a red filled rectangle) was replaced by the coding sequence of hrGFP followed by an SV40 polyadenylation signal $(\mathrm{pA})$. This specific transgenic line was derived from the RP24-80122 CRF BAC. CRF's and the transgene's transcriptional start sites $(+1)$, CRF's exons (denoted by numbered rectangles outlined in red), and the start codons (ATG) and stop codons (TGA or TAA) for CRF and hrGFP are all indicated. Panel B shows a schematic diagram of a coronal section of the mouse brain at the level where microphotographs were taken. Panel C shows low magnification merge microphotographs of hrGFP and CRF-IR signal within the amygdala of a colchicine-treated CRFhrGFP transgenic mouse. Panels D-F show high magnification microphotographs of the area marked in panel C. Panel D shows hrGFP in green, panel $E$ shows CRF-IR in red, and panel $F$ shows the merge of both images. White arrows point to dual-labeled cells. (For interpretation of the references to color in this figure legend, the reader is referred to the web version of this article.)

performed by an analysis of either endogenous hrGFP auto-fluorescence or further amplification of the signal achieved by an anti-hrGFP antibody followed by biotinylated secondary antibody, streptavidin-peroxidase, and a chromogenic reaction (Fig. 3). Both fluorescent and chromogenic signals showed very similar and consistent patterns of signal. However, chromogenic immunostaining made positive neurons more evident because the extra amplification steps of the reaction helped to enhance the signal particularly of faintly green fluorescent cells (Fig. 3). Thus, chromogenic hrGFP-IR signal was used for the detailed neuroanatomical analysis. The hrGFP-IR neurons were predominantly medium-sized, multipolar cells with intensely stained hrGFP-IR varicose terminals; and they were observed with a typical distribution at different rostro-caudal levels the amygdala (Fig. 3). In the anterior and middle levels of the amygdala, hrGFP-IR neurons were exclusively observed in the IPAC, mainly surrounding the dorsal part of the posterior limb of the anterior commissure (Fig. 3A, B, respectively). In contrast, hrGFP-IR neurons in the posterior level of the amygdala were observed not only in the IPAC but also in the CeA (Fig. 3C). On average, $1991 \pm 62$ hrGFP-IR neurons were detected hemilaterally within the amygdala region, with most of them $(92 \pm 1 \%)$ located within the IPAC.

\section{Functional characterization of hrGFP -expressing neurons of the amygdala in CRF-hrGFP mice}

After characterizing the distribution of hrGFP-expressing neurons within the amygdala, the induction of the marker of cellular activation C-Fos was assessed in CRF-hrGFP mice exposed to different experimental paradigms. These procedures were chosen based on two criteria: their reported ability to activate the amygdala, and their potential association with CRF signaling in this brain region. The performed tests included: i.p. LPS administration, an acute social defeat stress paradigm, a fasting/refeeding paradigm, an acute HFD protocol, an intermittent HFD protocol, a HFD withdrawal protocol, a conditioned HFD aversion protocol, an acute restraint stress protocol, a forced cold swimming stress protocol, ICV ghrelin administration, and ICV MC4R agonist administration. Firstly, we confirmed that the total number of c-Fos-IR cells in the amygdala of all experimental mice subjected to the different protocols was increased as compared to their corresponding control group, indicating that each procedure was successful in activating the region of interest (not shown). Interestingly, only CRF-hrGFP mice exposed to fasting/refeeding paradigm, acute social defeated stress or LPS administration showed a significant increase of hrGFP-neurons positive for c-Fos as compared to the levels found in control mice, the first condition being the one which elicited the strongest activation (Table 1 and Fig. 4). In all three cases, the hrGFP neurons positive for c-Fos were distributed throughout the whole rostro-caudal axis of the amygdala, without any particular pattern among hrGFP cells. The presence of these hrGFP neurons positive for c-Fos was mainly observed in the IPAC region (around $95 \%$ of all hrGFP neurons positive for c-Fos) while only few of them were found in the $\mathrm{CeA}$ (around $5 \%$ of all hrGFP neurons positive for c-Fos).

\section{DISCUSSION}

The current study provides the first neuroanatomical characterization of the distribution of the CRF neurons 

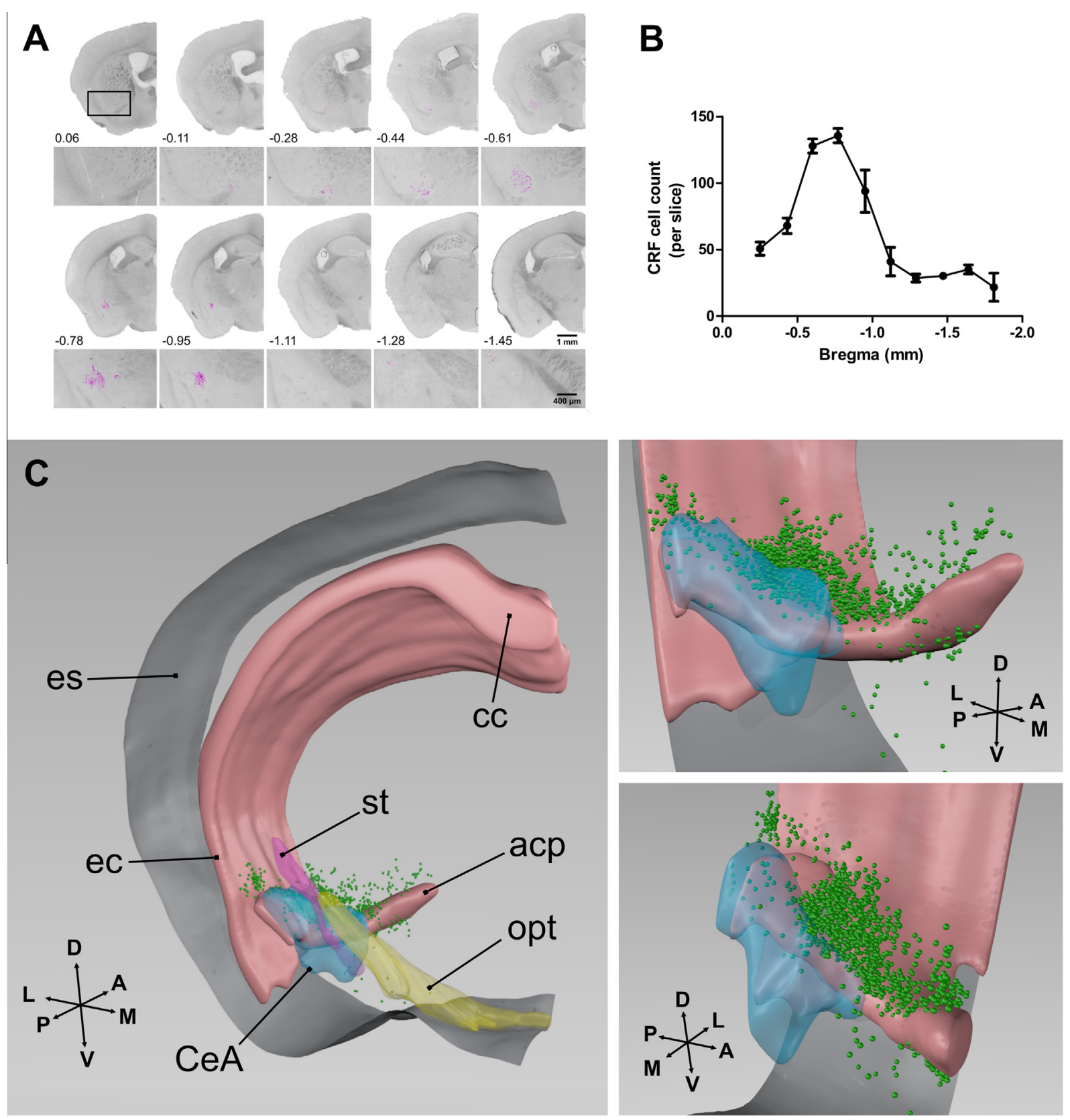

Fig. 2. Distribution pattern of hrGFP neurons within the amygdala of CRF-hrGFP mice. Panel A shows a composite of wide-field photographs of every 4th successive coronal brain slices, superimposed with fluorescence microscopy images of the hrGFP signal channel in magenta false coloring. The corresponding bregma coordinates for each slice are indicated, along with a higher magnification inset. Panel B shows a plot of the unilateral number of hrGFP-IR cells per slice in the bregma ranges from -0.25 to -1.81 . The values shown are the mean of $4-6$ measures, with their corresponding SEM. Panel C shows different views of a 3D reconstruction of the amygdalar region, generated from the whole series shown in panel A (39 slices in total). The position of every hrGFP-IR cell is marked by a green ball, along with the main white matter tracts [corpus callosum (cc), external capsule (ec), posterior limb of the anterior commissure (acp), stria terminalis (st), optic tract (opt)], the central amygdala (CeA) and the external surface of the brain (es). The left image shows a general view from a posterior position. The top and bottom right images show a close-up view of the amygdalar region from a posterior-medial and an antero-medial position, respectively, with the st and opt omitted for better clarity. Axes provide orientation of global coordinates: anterior, posterior, ventral, dorsal, medial and lateral.

within the amygdala of mice using a novel transgenic mouse line in which the hrGFP is under the control of the CRF promoter (CRF-hrGFP mice). The current study also demonstrates that amygdalar CRF neurons are activated by acute social defeated stress, a fasting/ refeeding paradigm or LPS administration, but not by other stimuli known to recruit amygdalar neurons.
A combination of histochemistry and fluorescence was used to validate the appropriate expression of hrGFP within the CRF neurons of the amygdala, and the majority of CRF neurons showed to express hrGFP. Notably, few green fluorescent neurons were detected in the PVN of CRF-hrGFP mice. The exact reasons for the limited hrGFP expression in the PVN are unclear, 
A
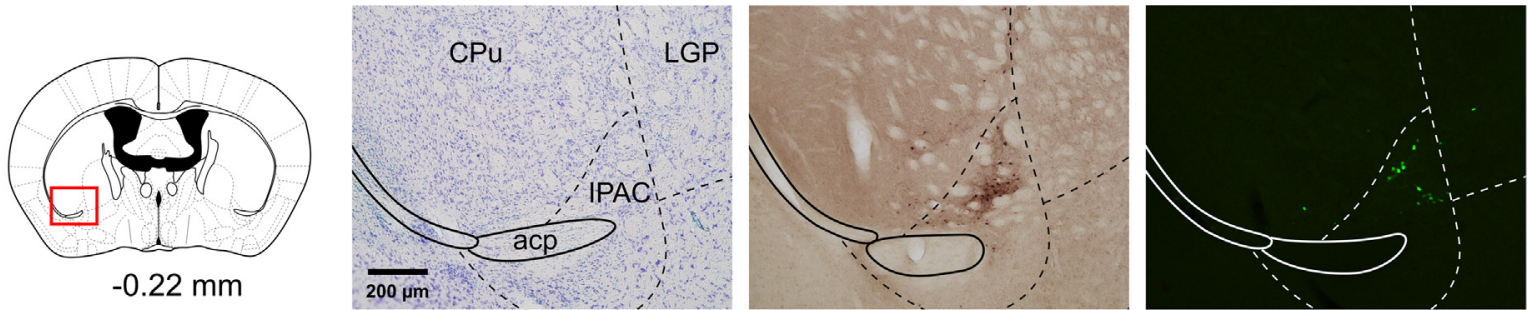

B
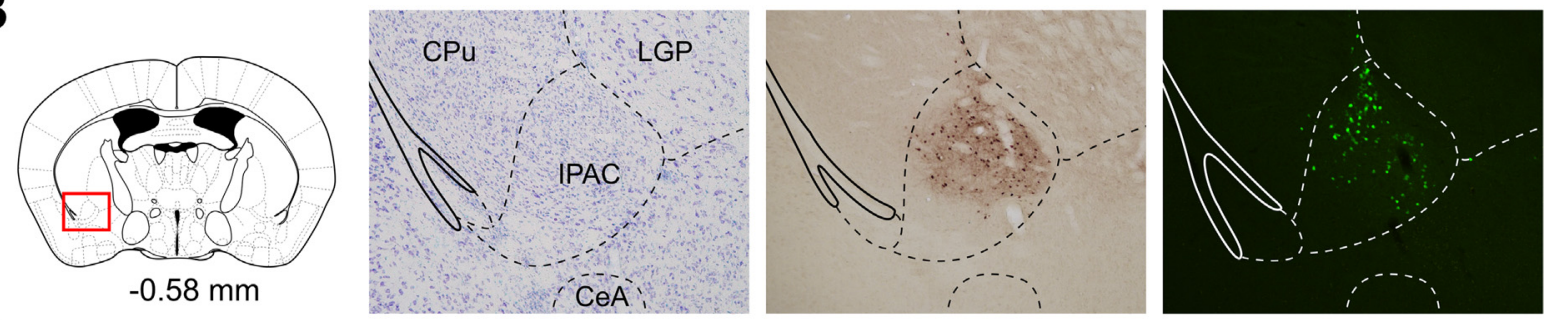

C

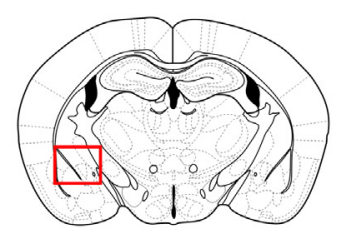

$-1.46 \mathrm{~mm}$
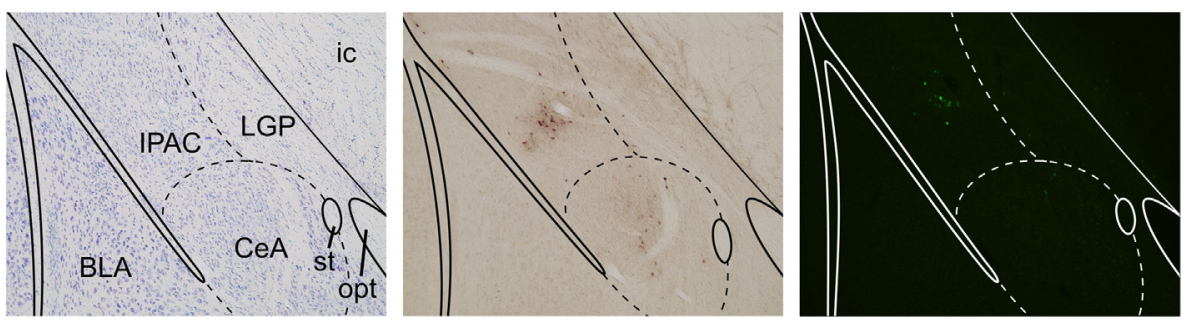

Fig. 3. Detailed pattern distribution of hrGFP neurons within the sub-nuclei of the amygdala of CRF-hrGFP mice. These panels depict a set of representative images from the anterior (bregma-0.22, Panel A), middle (bregma-0.58, Panel B), and posterior (bregma-1.46, Panel C) levels of the amygdala containing hrGFP neurons. For each level, a diagram of the corresponding coronal section is shown, with a rectangle indicating the approximate region from where the images were obtained, along with microphotographs of three consecutive coronal brain slices presented in the following order from left to right: Thionin-stained section, anti-hrGFP immunohistochemistry section, and hrGFP fluorescence microscopy section. Every image has an overlay delineating the main histological features present. IPAC: interstitial nucleus of the posterior limb of the anterior commissure, CPu: caudate putamen, LGP: lateral globus pallidus, acp: posterior limb of the anterior commissure, CeA: central amygdala, ic: internal capsule, BLA: basolateral amygdala, st: stria terminalis, opt: optic tract.

but might include chromosomal insertion site-related effects, failure of insertion of the entire BAC, unintended effects of removing the CRF coding sequence from the transgene, and/or lack of critical elements in the BAC necessaries for PVN gene expression (Matthaei, 2007; Gama Sosa et al., 2010). Regarding the last possibility, it is well known that different elements of the promoters can direct expression of the CRF gene in a brain nucleus-specific manner (Yoshida, 2008; Kageyama and Suda, 2009). Despite these considerations, which are known concerns for all transgenic mouse models, the CRF-hrGFP mouse described here appears as a useful tool for studying the role of CRF neurons within the amygdala.

The amygdala is a structurally and functionally complex brain region with extensive inter- and intranuclear connections (Sah et al., 2003). The CRF neurons represent an important neuronal population within the amygdala, and its physiological role is a focus of intensive research. Notably, the detailed neuroanatomical localization of CRF neurons within the mouse amygdala had not been performed. Current data show that the CRFexpressing cells in the amygdala are mainly observed in the IPAC with a smaller fraction of neurons within the $\mathrm{CeA}$. Although certain discrepancies exist in terms of the exact localization of CRF neurons within the rat
Table 1. Quantitative analysis of hrGFP neurons positive for c-Fos in the amygdala of the different experimental groups

\begin{tabular}{lc}
\hline Experimental condition & $\begin{array}{l}\text { hrGFP neurons positive for } \\
\text { C-Fos }(\%)\end{array}$ \\
\hline Control group 1 (non stressed) & $0 \pm 0$ \\
Control group 2 (regular chow & $0 \pm 0$ \\
fed) & \\
Control group 3 (vehicle, ICV) & $0 \pm 0$ \\
Vehicle, i.p. & $0 \pm 0$ \\
LPS, i.p. & $5.9 \pm 1.2^{* * *}$ \\
Acute social defeat stress & $7.4 \pm 1.6^{* * *}$ \\
Fasting/refeeding & $10.9 \pm 2.3^{* * *}$ \\
Fasting & $1.4 \pm 0.2$ \\
Acute HFD & $0.6 \pm 0.6$ \\
Intermittent HFD & $1.6 \pm 0.5$ \\
HFD ad libitum & $0 \pm 0$ \\
HFD withdrawal & $0 \pm 0$ \\
Conditioned HFD aversion & $0 \pm 0$ \\
Control of conditioned HFD & $0 \pm 0$ \\
$\quad$ aversion test & $0 \pm 0$ \\
Acute restraint stress & $0 \pm 0$ \\
Forced cold swimming test & $0.2 \pm 0.1$ \\
Ghrelin, ICV & $0 \pm 0$ \\
MC4R agonist RO 27-3225, & \\
ICV & \\
\hline
\end{tabular}

${ }^{* * *} p<0.01$ vs. corresponding control group. 

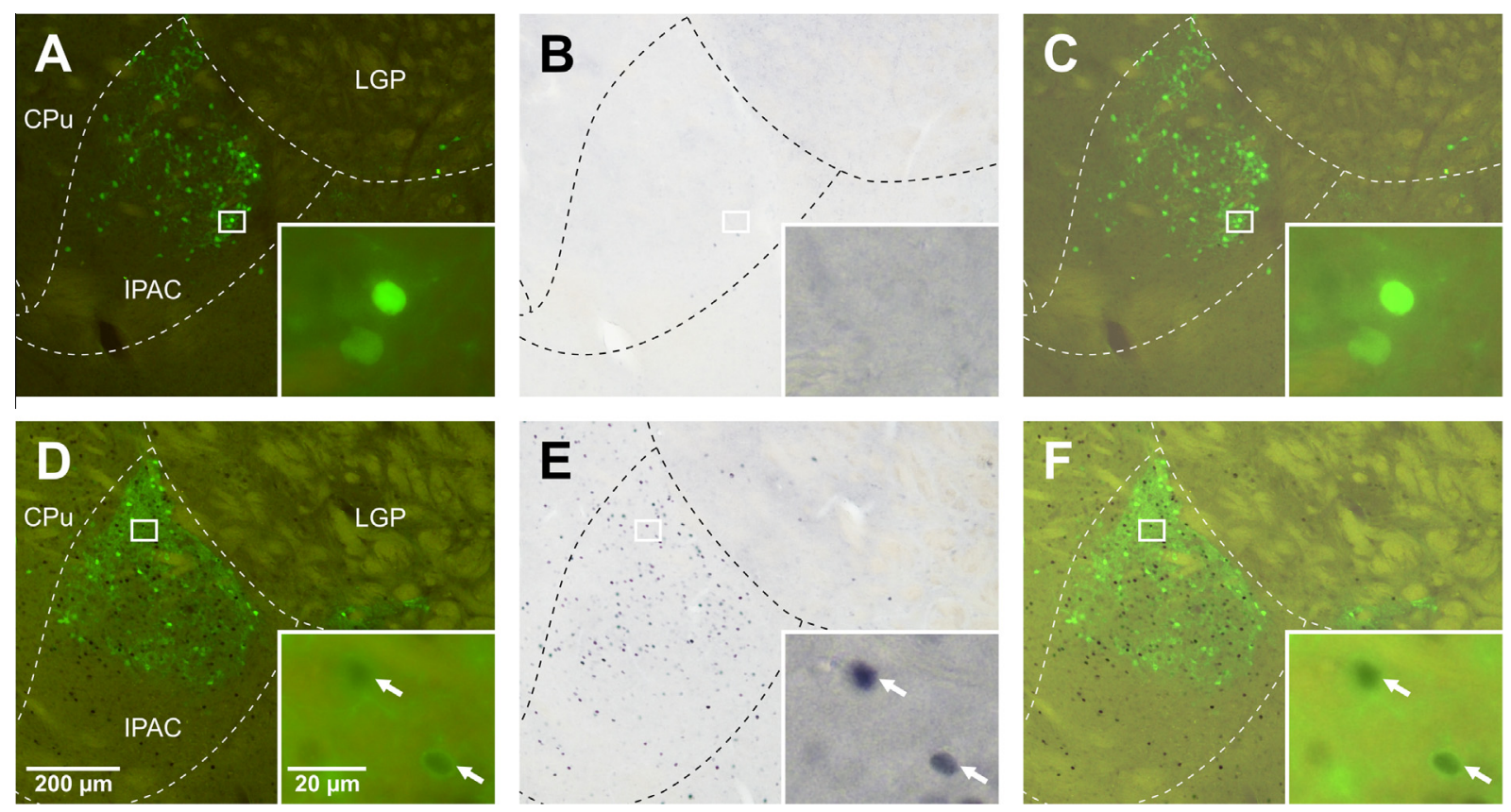

Fig. 4. Fasting/refeeding protocol activates amygdala hrGFP neurons in CRF-hrGFP mice. CRF-hrGFP mice were food deprived for $48 \mathrm{~h}$, and then were either perfused or given access to food for $2 \mathrm{~h}$ and then perfused. c-Fos IHC was performed on coronal brain sections, and colocalization for hrGFP and c-Fos was evaluated by fluorescence and bright-field microscopy. Representative images of the amygdala region at bregma $-0.58 \mathrm{~mm}$ of a control (panels A-C) and a refed mouse (panels D-F) are shown. Upper and bottom set of panels show fluorescence of hrGFP (left), staining for c-Fos (middle) and a merge of both (right), along with their corresponding insets at higher magnification. Colocalization of c-Fos and hrGFP is indicated by the white arrows. IPAC: interstitial nucleus of the posterior limb of the anterior commissure, CPu: caudate putamen, LGP: lateral globus pallidus.

amygdala, most studies have shown that the CeA contains the largest number of CRF neurons while other amygdalar nuclei contain only a small number of such neurons (Swanson et al., 1983; Bugnon et al., 1984; Veening et al., 1984; Sakanaka et al., 1986, 1987; Shimada et al., 1989). In contrast, the largest number of CRF neurons is found in the basal and lateral nuclei of the amygdala of the squirrel monkey (Bassett and Foote, 1992). In mice, and less prominently in rats, CRF mRNA-reactive neurons were reported antero-dorsal to the amygdala in the region of the IPAC and in the amygdalo-striatal transition area, with variations between the strains (Asan et al., 2005). Thus, the relative distribution of CRF neurons within the amygdala differs among species and even within strains of the same species, as a consequence, data from different animal models should be integrated with caution.

Mapping c-Fos induction has been widely and successfully used in the past to map neuronal activation and to determine the participation of specific neuronal subsets in different neural circuits (Hoffman and Lyo, 2002). This has not been the case, however, for the CRF neurons of the amygdala given their difficult identification in a physiologically functional context. In the present work we take advantage of this new transgenic CRF reporter mouse model to gain insights into the involvement of the CRF neurons of the amygdala in the responses elicited by different experimental paradigms, using c-Fos as a surrogate marker for neuronal activation. Nonetheless, it is important to stress the fact that the absence of c-Fos expression in CRF neurons of the amygdala under some experimental conditions, particularly those involving chronic processes, is not proof that these neurons are not involved in a given response. (Hoffman and Lyo, 2002).

The CRF system of the amygdala has been implicated in the regulation of aversion and rewarding behaviors (George et al., 2012; Zorrilla et al., 2014). For instance, cocaine administration increases both CRF expression and release in the amygdala (Sarnyai et al., 1993; Richter et al., 1995; Gardi et al., 1997). Increases in the activity of the amygdalar CRF system has been also shown during the early cocaine withdrawal phase in cocaine-trained rats (Erb and Stewart, 1999; Zhou et al., 2003). Although less clear, some evidence suggests that these CRF neurons play a role in the regulation of foodrelated rewarding behaviors. It has been shown, for instance, that amygdala lesions decrease HFD preference (King et al., 1998), exposure to palatable foods induces c-Fos in the CeA (Park and Carr, 1998), and food intake induces CRF release in the CeA (Merali et al., 1998). In order to test if the CRF neurons of the amygdala are recruited by palatable foods, CRF-hrGFP mice were exposed to a number of paradigms in which HFD was used as a rewarding stimulus. Analysis of c-Fos induction showed that CRF neurons failed to increase this marker of neuronal activation after acute HFD consumption, intermittent HFD consumption, ad libitum HFD consumption, HFD withdrawal after 2 weeks of ad libitum HFD consumption or conditioned HFD aversion. Notably, c-Fos in the amygdala was significantly increased under all these experimental conditions suggesting that the 
amygdala is indeed involved. However, other non-CRF neuronal populations of the amygdala seem to be recruited by these conditions. As stated above, the absence of c-Fos induction within the CRF neurons of the amygdala when HFD consumption was manipulated is not proof of the absence of their engagement in a given neuronal circuit. However, the fact that c-Fos increase within CRF neurons in response to other stimulus does support the possibility that these neurons of the amygdala play a rather minor role on these HFD-related behaviors.

It is well-known that the CRF system of the amygdala is involved in stress responses (LeDoux, 2007; Kovács, 2013). Here, we confirmed that acute social defeat stress, restraint stress, immune challenge, and forced swim stress all elicited an increase of c-Fos levels in the amygdala, as previously reported (Dayas et al., 2001; Martinez et al., 2002). However, c-Fos induction in the CRF neurons of the amygdala was detected only in response to specific challenges. Exposure of CRF-hrGFP mice to the forced cold swim stress or acute restraint stress, which are both experimental models for psychological stress (Glavin et al., 1994), failed to activate c-Fos in the CRF neurons of the amygdala. In contrast, CRFhrGFP mice exposed to either acute social defeat stress or immune challenge showed a robust increase of the c-Fos expression in the CRF neurons of the amygdala. A single event in the resident-intruder paradigm of social defeat, in which the experimental animal is exposed to a non-lethal aggression, is sufficient to induce behavioral changes that persist for weeks, and the CRF system of the amygdala has been show to modulate agonistic behavior following social defeat (Tornatzky and Miczek, 1993; Meerlo et al., 1999; Jasnow et al., 2004; Robison et al., 2004). Thus, the current results confirm that the CRF neurons of the amygdala are recruited by acute social defeat stress. On the other hand, it has been suggested that the amygdala mediates LPS effects on a number of brain functions, including reduction of exploratory behaviors toward novel objects (Haba et al., 2012). In fact, administration of LPS triggers activation of the $\mathrm{CeA}$ mediated by vagal stimulation, and induces depressivelike behaviors in rats (Konsman et al., 2000). Current data point at the CRF neurons of the amygdala as a target of the neuronal systems activated by an immune challenge. Overall, these observations show that the CRF neurons of the amygdala play a differential role in response to diverse experimental conditions, supporting the notion that the neuronal circuits engaged by stress within the amygdala are stressor-specific.

The amygdala is known to be involved in food intake regulation (Baxter and Murray, 2002; Will et al., 2009). The MC4R, which mediates anorexigenic effects provided by the pro-opiomelanocortin-derived peptide $\alpha$-melanocyte stimulating hormone, is highly expressed in the amygdala (Kishi et al., 2003), and central administration of an MC4R agonist strongly increases c-Fos expression in the amygdala (Agosti et al., 2014). The key role of the amygdala in mediating the anorectic effects of the MC4R signaling is highlighted by the finding that the re-expression of MC4R exclusively in the PVN and amygdala is sufficient to restore food intake and partially prevent obesity in MC4R-deficient mice (Balthasar et al., 2005). The current study shows, however, that MC4R agonist administration to CRF-hrGFP mice fails to activate c-Fos in the CRF neurons of the amygdala suggesting that other neuronal populations of the amygdala mediate the anorexic effect of MC4R signaling in this brain area. Interestingly, the amygdala has also been shown to be a target of the orexigenic hormone ghrelin. In particular, the amygdala has been suggested to mediate ghrelin's roles in the modulation of food reward and learning (Alvarez-Crespo et al., 2012). Indeed, a human functional MRI study showed that ghrelin activates the amygdala upon exposure to images of appealing foods (Malik et al., 2008), and ghrelin receptor is expressed in the amygdala (Mani et al., 2014). Despite that a significant increase of c-Fos was detected in the amygdala of ghrelin-treated mice, no c-Fos was detected in the CRF neurons of this brain region also suggesting that other neuronal populations of the amygdala mediate ghrelin's effects.

Food intake regulation involves the integration of orexigenic and anorexigenic neuronal circuits that drive or stop feeding, respectively, depending on the energy needs. Fasting activates orexigenic neuronal pathways that drive hyperphagia when animals have access to food, while refeeding activates neuronal pathways involved in the termination of a meal (Grill and Kaplan, 2002). It is well established that brainstem and hypothalamic pathways have a critical role in the regulation of meal size. However, recent evidences also show that other brain regions, including the amygdala, are important in acute appetite regulation (Wu et al., 2014). In particular, a recent study using genetically encoded anatomical, optogenetic and pharmacogenetic tools have showed that a parabrachial nucleus-amygdala pathway is essential to suppress appetite after refeeding (Carter et al., 2013). However, the phenotype of the amygdalar neurons activated by refeeding is unknown. The current study not only confirms that refeeding after fasting activates c-Fos in the amygdala, as previously reported (Timofeeva et al., 2002; Wu et al., 2014), but also shows that CRF neurons of the amygdala are one of the neuronal cell types activated in this condition. In line with this possibility, it had been shown that CRF mRNA levels in the amygdala decreased during food deprivation and gradually returned to predeprivation values during refeeding in rats (Timofeeva et al., 2002). Furthermore, microdialysis experiments have shown a rise in amygdalar CRF during the prandial and postprandial phases of a spontaneous meal in rats (Merali et al., 1998), a pattern congruent with a potential suppressive role of CRF on feeding. It is interesting to note, however, that the physiological role of CRF as an anorectic peptide has been a matter of debate. Central administration of CRF potently inhibits food intake in rodents, and the CRF system has been suggested to play an essential role as mediator of stress-induced anorexia (Koob and Heinrichs, 1999; Richard et al., 2002; Zorrilla et al., 2003). However, CRF-deficient mice display a similar decrease in food intake when compared to wild-type mice under the same stress conditions (i.e. repetitive daily restraint, turpentine abscess or surgical stress), which may highlight the importance of other members of the 
CRF system (such as urocortins) as mediators of appetite reduction (Weninger et al., 1999). These seemingly antagonizing results may also reflect the complexity of this regulatory system, stressing the importance of the local context of action of these peptides and its developmental adaptative mechanisms. In the current study, activation of the CRF neurons of the amygdala was also detected after LPS administration or acute social defeat, two experimental conditions which also decrease food intake (Meerlo et al., 1999; Konsman et al., 2000). Although it would be tempting to draw a parallelism with the fasting/refeeding paradigm in this regard, caution should be exerted when performing generalizations, as other paradigms that failed to induce c-Fos in CRF neurons of the amygdala, such as acute restraint or forced swimming, also suppress food intake. Overall, current data suggest a link between CRF neurons of the amygdala and food intake suppression after some particular experimental conditions; however, more studies will be necessary to specifically test this possibility. Hopefully, the CRF-hrGFP mouse model reported here will be a useful tool to perform further studies that will help to clarify the physiological role of the CRF system of the amygdala.

Acknowledgements-This work was supported by grants of the National Agency of Scientific and Technological Promotion of Argentina (PICT2010-1954 and PICT2011-2142) to MP, the NIH (R03TW008925-01A1) to MP and JMZ, and (R01MH085298) to JMZ. We want to thank Guadalupe Garcia Romero and Anabela Patrone for their technical support.

\section{REFERENCES}

Abercrombie M (1946) Estimation of nuclear population from microtome sections. Anat Rec 94:239-247.

Agosti F, López Soto EJ, Cabral A, Castrogiovanni D, Schioth HB, Perelló M, Raingo J (2014) Melanocortin 4 receptor activation inhibits presynaptic N-type calcium channels in amygdaloid complex neurons. Eur J Neurosci 40:2755-2765. http:/l dx. doi.org/10.1111/ejn.12650.

Alon T, Zhou L, Pérez CA, Garfield AS, Friedman JM, Heisler LK (2009) Transgenic mice expressing green fluorescent protein under the control of the corticotropin-releasing hormone promoter. Endocrinology 150:5626-5632. http://dx.doi.org/10.1210/ en.2009-0881.

Alvarez-Crespo M, Skibicka KP, Farkas I, Molnár CS, Egecioglu E, Hrabovszky E, Liposits Z, Dickson SL (2012) The amygdala as a neurobiological target for ghrelin in rats: neuroanatomical, electrophysiological and behavioral evidence. PLoS One 7:e46321. http://dx.doi.org/10.1371/journal.pone.0046321.

Asan E, Yilmazer-Hanke DM, Eliava M, Hantsch M, Lesch K-P, Schmitt A (2005) The corticotropin-releasing factor (CRF)-system and monoaminergic afferents in the central amygdala: investigations in different mouse strains and comparison with the rat. Neuroscience 131:953-967. http://dx.doi.org/10.1016/ j.neuroscience. 2004.11.040.

Bale TL, Vale WW (2004) CRF and CRF receptors: role in stress responsivity and other behaviors. Annu Rev Pharmacol Toxicol 44:525-557.

http://dx.doi.org/10.1146/ annurev.pharmtox.44.101802.121410.

Balthasar N, Dalgaard LT, Lee CE, Yu J, Funahashi H, Williams T, Ferreira M, Tang V, McGovern RA, Kenny CD, Christiansen LM, Edelstein E, Choi B, Boss O, Aschkenasi C, Zhang C, Mountjoy K, Kishi T, Elmquist JK, Lowell BB (2005) Divergence of melanocortin pathways in the control of food intake and energy expenditure. Cell 123:493-505. http://dx.doi.org/10.1016/ i.cell.2005.08.035.

Bassett JL, Foote SL (1992) Distribution of corticotropin-releasing factor-like immunoreactivity in squirrel monkey (Saimiri sciureus) amygdala. J Comp Neurol 323:91-102. http://dx.doi.org/10.1002/ cne.903230108.

Baxter MG, Murray EA (2002) The amygdala and reward. Nat Rev Neurosci 3:563-573. http://dx.doi.org/10.1038/nrn875.

Berner LA, Avena NM, Hoebel BG (2008) Bingeing, self-restriction, and increased body weight in rats with limited access to a sweetfat diet. Obesity (Silver Spring) 16:1998-2002. http://dx.doi.org/ 10.1038/oby.2008.328.

Bugnon C, Fellmann D, Gouget A, Bresson JL, Clavequin MC, Hadjiyiassemis M, Cardot J (1984) Corticoliberin neurons: cytophysiology, phylogeny and ontogeny. J Steroid Biochem 20:183-195.

Cardona A, Saalfeld S, Schindelin J, Arganda-Carreras I, Preibisch S, Longair M, Tomancak P, Hartenstein V, Douglas RJ (2012) TrakEM2 software for neural circuit reconstruction. PLoS One 7:e38011. http://dx.doi.org/10.1371/journal.pone.0038011.

Carlin KM, Vale WW, Bale TL (2006) Vital functions of corticotropinreleasing factor (CRF) pathways in maintenance and regulation of energy homeostasis. Proc Natl Acad Sci USA 103:3462-3467. http://dx.doi.org/10.1073/pnas.0511320103.

Carter ME, Soden ME, Zweifel LS, Palmiter RD (2013) Genetic identification of a neural circuit that suppresses appetite. Nature 503:111-114. http://dx.doi.org/10.1038/nature12596.

Cassell MD, Gray TS, Kiss JZ (1986) Neuronal architecture in the rat central nucleus of the amygdala: a cytological, hodological, and immunocytochemical study. J Comp Neurol 246:478-499. http:// dx.doi.org/10.1002/cne.902460406.

Chen X, Herbert J (1995) Regional changes in c-fos expression in the basal forebrain and brainstem during adaptation to repeated stress: correlations with cardiovascular, hypothermic and endocrine responses. Neuroscience 64:675-685.

Chuang J-C, Perello M, Sakata I, Osborne-Lawrence S, Savitt JM, Lutter M, Zigman JM (2011) Ghrelin mediates stress-induced food-reward behavior in mice. J Clin Invest 121:2684-2692. http:// dx.doi.org/10.1172/JCl57660.

Dayas CV, Buller KM, Crane JW, Xu Y, Day TA (2001) Stressor categorization: acute physical and psychological stressors elicit distinctive recruitment patterns in the amygdala and in medullary noradrenergic cell groups. Eur J Neurosci 14:1143-1152.

Erb S, Stewart J (1999) A role for the bed nucleus of the stria terminalis, but not the amygdala, in the effects of corticotropinreleasing factor on stress-induced reinstatement of cocaine seeking. J Neurosci 19:RC35.

Gafford G, Jasnow AM, Ressler KJ (2014) Grin1 receptor deletion within CRF neurons enhances fear memory. PLoS One 9:e111009. http://dx.doi.org/10.1371/journal.pone.0111009.

Gama Sosa MA, De Gasperi R, Elder GA (2010) Animal transgenesis: an overview. Brain Struct Funct 214:91-109. http://dx.doi.org/10.1007/s00429-009-0230-8.

Gardi J, Bíró E, Sarnyai Z, Vecsernyés M, Julesz J, Telegdy G (1997) Time-dependent alterations in corticotropin-releasing factor-like immunoreactivity in different brain regions after acute cocaine administration to rats. Neuropeptides 31:15-18.

George O, Le Moal M, Koob GF (2012) Allostasis and addiction: role of the dopamine and corticotropin-releasing factor systems. Physiol Behav 106:58-64. http://dx.doi.org/10.1016/ j.physbeh.2011.11.004.

Glavin GB, Paré WP, Sandbak T, Bakke HK, Murison R (1994) Restraint stress in biomedical research: an update. Neurosci Biobehav Rev 18:223-249.

Gray TS (1999) Functional and anatomical relationships among the amygdala, basal forebrain, ventral striatum, and cortex. An integrative discussion. Ann N Y Acad Sci 877:439-444.

Grill HJ, Kaplan JM (2002) The neuroanatomical axis for control of energy balance. Front Neuroendocrinol 23:2-40. http://dx.doi.org/ 10.1006/frne.2001.0224. 
Haba R, Shintani N, Onaka Y, Wang H, Takenaga R, Hayata A, Baba A, Hashimoto H (2012) Lipopolysaccharide affects exploratory behaviors toward novel objects by impairing cognition and/or motivation in mice: possible role of activation of the central amygdala. Behav Brain Res 228:423-431. http://dx.doi.org/ 10.1016/j.bbr.2011.12.027.

Hansson C, Alvarez-Crespo M, Taube M, Skibicka KP, Schmidt L, Karlsson-Lindahl L, Egecioglu E, Nissbrandt H, Dickson SL (2014) Influence of ghrelin on the central serotonergic signaling system in mice. Neuropharmacology 79:498-505. http:/l dx.doi.org/10.1016/i.neuropharm.2013.12.012.

Heinrichs SC, Koob GF (2006). Application of experimental stressors in laboratory rodents. Curr Protoc Neurosci Editor. Board Jacqueline N Crawley Al Chapter 8, Unit8.4. doi: 10.1002/ 0471142301.ns0804s34.

Hoffman GE, Lyo D (2002) Anatomical markers of activity in neuroendocrine systems: are we all "fos-ed out"? J Neuroendocrinol 14:259-268.

Itoi K, Talukder AH, Fuse T, Kaneko T, Ozawa R, Sato T, Sugaya T, Uchida K, Yamazaki M, Abe M, Natsume R, Sakimura K (2014) Visualization of corticotropin-releasing factor neurons by fluorescent proteins in the mouse brain and characterization of labeled neurons in the paraventricular nucleus of the hypothalamus. Endocrinology 155:4054-4060. http://dx.doi.org/ 10.1210/en.2014-1182.

Jasnow AM, Davis M, Huhman KL (2004) Involvement of central amygdalar and bed nucleus of the stria terminalis corticotropinreleasing factor in behavioral responses to social defeat. Behav Neurosci 118:1052-1061. http://dx.doi.org/10.1037/07357044.118.5.1052.

Kageyama K, Suda T (2009) Regulatory mechanisms underlying corticotropin-releasing factor gene expression in the hypothalamus. Endocr J 56:335-344.

King BM, Rossiter KN, Stines SG, Zaharan GM, Cook JT, Humphries MD, York DA (1998) Amygdaloid-lesion hyperphagia: impaired response to caloric challenges and altered macronutrient selection. Am J Physiol 275:R485-R493.

Kishi T, Aschkenasi CJ, Lee CE, Mountjoy KG, Saper CB, Elmquist JK (2003) Expression of melanocortin 4 receptor mRNA in the central nervous system of the rat. J Comp Neurol 457:213-235. http://dx.doi.org/10.1002/cne.10454.

Konsman JP, Luheshi GN, Bluthé RM, Dantzer R (2000) The vagus nerve mediates behavioural depression, but not fever, in response to peripheral immune signals; a functional anatomical analysis. Eur J Neurosci 12:4434-4446.

Koob GF, Heinrichs SC (1999) A role for corticotropin releasing factor and urocortin in behavioral responses to stressors. Brain Res 848:141-152.

Kovács KJ (2013) CRH: the link between hormonal-, metabolic- and behavioral responses to stress. J Chem Neuroanat 54:25-33. http://dx.doi.org/10.1016/j.jchemneu.2013.05.003.

Kozak W, Conn CA, Kluger MJ (1994) Lipopolysaccharide induces fever and depresses locomotor activity in unrestrained mice. Am J Physiol 266:R125-R135.

LeDoux J (2007) The amygdala. Curr Biol 17:R868-R874. http:// dx.doi.org/10.1016/i.cub.2007.08.005.

Lee EC, Yu D, Martinez de Velasco J, Tessarollo L, Swing DA, Court DL, Jenkins NA, Copeland NG (2001) A highly efficient Escherichia coli-based chromosome engineering system adapted for recombinogenic targeting and subcloning of BAC DNA. Genomics 73:56-65. http://dx.doi.org/10.1006/ geno.2000.6451.

Malik S, McGlone F, Bedrossian D, Dagher A (2008) Ghrelin modulates brain activity in areas that control appetitive behavior. Cell Metab 7:400-409. http://dx.doi.org/10.1016/ j.cmet.2008.03.007.

Mani BK, Walker AK, Lopez Soto EJ, Raingo J, Lee CE, Perelló M, Andrews ZB, Zigman JM (2014) Neuroanatomical characterization of a growth hormone secretagogue receptorgreen fluorescent protein reporter mouse. J Comp Neurol 522:3644-3666. http://dx.doi.org/10.1002/cne.23627.
Marchant NJ, Densmore VS, Osborne PB (2007) Coexpression of prodynorphin and corticotrophin-releasing hormone in the rat central amygdala: evidence of two distinct endogenous opioid systems in the lateral division. J Comp Neurol 504:702-715. http://dx.doi.org/10.1002/cne.21464.

Martin EI, Ressler KJ, Jasnow AM, Dabrowska J, Hazra R, Rainnie DG, Nemeroff CB, Owens MJ (2010) A novel transgenic mouse for gene-targeting within cells that express corticotropin-releasing factor. Biol Psychiatry 67:1212-1216. http://dx.doi.org/10.1016/ j.biopsych.2010.01.026.

Martinez M, Phillips PJ, Herbert J (1998) Adaptation in patterns of cfos expression in the brain associated with exposure to either single or repeated social stress in male rats. Eur $\mathrm{J}$ Neurosci 10:20-33.

Martinez M, Calvo-Torrent A, Herbert J (2002) Mapping brain response to social stress in rodents with c-fos expression: a review. Stress 5:3-13. http://dx.doi.org/10.1080/ 102538902900012369.

Matthaei KI (2007) Genetically manipulated mice: a powerful tool with unsuspected caveats. J Physiol 582:481-488. http://dx.doi.org/ 10.1113/iphysiol.2007.134908.

Meerlo P, Sgoifo A, De Boer SF, Koolhaas JM (1999) Long-lasting consequences of a social conflict in rats: behavior during the interaction predicts subsequent changes in daily rhythms of heart rate, temperature, and activity. Behav Neurosci 113:1283-1290.

Merali Z, McIntosh J, Kent P, Michaud D, Anisman H (1998) Aversive and appetitive events evoke the release of corticotropin-releasing hormone and bombesin-like peptides at the central nucleus of the amygdala. J Neurosci 18:4758-4766.

Muyrers JP, Zhang Y, Stewart AF (2001) Techniques: recombinogenic engineering-new options for cloning and manipulating DNA. Trends Biochem Sci 26:325-331.

Nomura M, Saito J, Ueta Y, Muglia LJ, Pfaff DW, Ogawa S (2003) Enhanced up-regulation of corticotropin-releasing hormone gene expression in response to restraint stress in the hypothalamic paraventricular nucleus of oxytocin gene-deficient male mice. $J$ Neuroendocrinol 15:1054-1061.

Park TH, Carr KD (1998) Neuroanatomical patterns of fos-like immunoreactivity induced by a palatable meal and meal-paired environment in saline- and naltrexone-treated rats. Brain Res 805:169-180.

Paxinos G, Franklin KBJ (2001) The mouse brain in stereotaxic coordinates. 2nd ed. San Diego: Academic Press.

Perelló M, Giovambattista A, Castrogiovanni D, Gaillard RC, Spinedi E (2011) Modulatory role of the ovarian function in neuroimmunoendocrine axis activity. NeurolmmunoModulation 18:19-27. http://dx.doi.org/10.1159/000314608.

Retson TA, Hoek JB, Sterling RC, Van Bockstaele EJ (2014) Amygdalar neuronal plasticity and the interactions of alcohol, sex, and stress. Brain Struct Funct. http://dx.doi.org/10.1007/ s00429-014-0851-4.

Richard D, Lin Q, Timofeeva E (2002) The corticotropin-releasing factor family of peptides and CRF receptors: their roles in the regulation of energy balance. Eur J Pharmacol 440:189-197.

Richter RM, Pich EM, Koob GF, Weiss F (1995) Sensitization of cocaine-stimulated increase in extracellular levels of corticotropinreleasing factor from the rat amygdala after repeated administration as determined by intracranial microdialysis. Neurosci Lett 187:169-172.

Robison CL, Meyerhoff JL, Saviolakis GA, Chen WK, Rice KC, Lumley LA (2004) A CRH1 antagonist into the amygdala of mice prevents defeat-induced defensive behavior. Ann N Y Acad Sci 1032:324-327. http://dx.doi.org/10.1196/annals.1314.052.

Sah P, Faber ESL, Lopez De Armentia M, Power J (2003) The amygdaloid complex: anatomy and physiology. Physiol Rev 83:803-834. http://dx.doi.org/10.1152/physrev.00002.2003.

Sakanaka M, Shibasaki T, Lederis K (1986) Distribution and efferent projections of corticotropin-releasing factor-like immunoreactivity in the rat amygdaloid complex. Brain Res 382:213-238.

Sakanaka M, Shibasaki T, Lederis K (1987) Improved fixation and cobalt-glucose oxidase-diaminobenzidine intensification for 
immunohistochemical demonstration of corticotropin-releasing factor in rat brain. J Histochem Cytochem 35:207-212.

Sarnyai Z, Bíró E, Gardi J, Vecsernyés M, Julesz J, Telegdy G (1993) Alterations of corticotropin-releasing factor-like immunoreactivity in different brain regions after acute cocaine administration in rats. Brain Res 616:315-319.

Schindelin J, Arganda-Carreras I, Frise E, Kaynig V, Longair M, Pietzsch T, Preibisch S, Rueden C, Saalfeld S, Schmid B, Tinevez J-Y, White DJ, Hartenstein V, Eliceiri K, Tomancak P, Cardona A (2012) Fiji: an open-source platform for biologicalimage analysis. Nat Methods 9:676-682. http://dx.doi.org/ 10.1038/nmeth.2019.

Shimada S, Inagaki S, Kubota Y, Ogawa N, Shibasaki T, Takagi H (1989) Coexistence of peptides (corticotropin releasing factor/ neurotensin and substance $\mathrm{P} /$ somatostatin) in the bed nucleus of the stria terminalis and central amygdaloid nucleus of the rat. Neuroscience 30:377-383.

Skelly DT, Hennessy E, Dansereau M-A, Cunningham C (2013) A systematic analysis of the peripheral and CNS effects of systemic LPS, IL-1 $\beta$, [corrected] TNF- $\alpha$ and IL- 6 challenges in C57BL/6 mice. PLoS One 8:e69123. http://dx.doi.org/10.1371/ journal.pone.0069123.

Spencer CM, Eckel LA, Nardos R, Houpt TA (2012) Area postrema lesions attenuate $\mathrm{LiCl}$-induced $\mathrm{c}-\mathrm{Fos}$ expression correlated with conditioned taste aversion learning. Physiol Behav 105:151-160. http://dx.doi.org/10.1016/j.physbeh.2011.08.022.

Swanson LW, Sawchenko PE, Rivier J, Vale WW (1983) Organization of ovine corticotropin-releasing factor immunoreactive cells and fibers in the rat brain: an immunohistochemical study. Neuroendocrinology 36:165-186.

Tarr AJ, Chen Q, Wang Y, Sheridan JF, Quan N (2012) Neural and behavioral responses to low-grade inflammation. Behav Brain Res 235:334-341. http://dx.doi.org/10.1016/j.bbr.2012.07.038.

Timofeeva E, Picard F, Duclos M, Deshaies Y, Richard D (2002) Neuronal activation and corticotropin-releasing hormone expression in the brain of obese (fa/fa) and lean (fa/?) Zucker rats in response to refeeding. Eur J Neurosci 15:1013-1029.

Tornatzky W, Miczek KA (1993) Long-term impairment of autonomic circadian rhythms after brief intermittent social stress. Physiol Behav 53:983-993.

Valdivia S, Patrone A, Reynaldo M, Perello M (2014) Acute high fat diet consumption activates the mesolimbic circuit and requires orexin signaling in a mouse model. PLoS One 9:e87478. http:// dx.doi.org/10.1371/journal.pone.0087478.

Vale W, Rivier C, Brown MR, Spiess J, Koob G, Swanson L, Bilezikjian L, Bloom F, Rivier J (1983) Chemical and biological characterization of corticotropin releasing factor. Recent Prog Horm Res 39:245-270.

Veening JG, Swanson LW, Sawchenko PE (1984) The organization of projections from the central nucleus of the amygdala to brainstem sites involved in central autonomic regulation: a combined retrograde transport-immunohistochemical study. Brain Res 303:337-357.

Walker AK, Budac DP, Bisulco S, Lee AW, Smith RA, Beenders B, Kelley KW, Dantzer R (2013) NMDA receptor blockade by ketamine abrogates lipopolysaccharide-induced depressive-like behavior in C57BL/6J mice. Neuropsychopharmacology 38:1609-1616. http://dx.doi.org/10.1038/npp.2013.71.

Wamsteeker Cusulin JI, Füzesi T, Watts AG, Bains JS (2013) Characterization of corticotropin-releasing hormone neurons in the paraventricular nucleus of the hypothalamus of Crh-IRES-Cre mutant mice. PLoS One 8:e64943. http://dx.doi.org/10.1371/ journal.pone.0064943.

Weninger SC, Muglia LJ, Jacobson L, Majzoub JA (1999) CRHdeficient mice have a normal anorectic response to chronic stress. Regul Pept 84:69-74.

Will MJ, Pritchett CE, Parker KE, Sawani AM, Ma H, Lai AY (2009) Behavioral characterization of amygdala involvement in mediating intra-accumbens opioid-driven feeding behavior. Behav Neurosci 123:781-793. http://dx.doi.org/10.1037/a0016060.

Wu Q, Lemus MB, Stark R, Bayliss JA, Reichenbach A, Lockie SH, Andrews ZB (2014) The temporal pattern of cfos activation in hypothalamic, cortical, and brainstem nuclei in response to fasting and refeeding in male mice. Endocrinology 155:840-853. http:// dx.doi.org/10.1210/en.2013-1831.

Yoshida M (2008) Gene regulation system of vasopressin and corticotropin-releasing hormone. Gene Regul Syst Biol 2:71-88.

Zhou Y, Spangler R, Ho A, Kreek MJ (2003) Increased CRH mRNA levels in the rat amygdala during short-term withdrawal from chronic "binge" cocaine. Brain Res Mol Brain Res 114:73-79.

Zhu L, Wu L, Yu B, Liu X (2011) The participation of a neurocircuit from the paraventricular thalamus to amygdala in the depressive like behavior. Neurosci Lett 488:81-86. http://dx.doi.org/10.1016/ j.neulet.2010.11.007.

Zorrilla EP, Taché Y, Koob GF (2003) Nibbling at CRF receptor control of feeding and gastrocolonic motility. Trends Pharmacol Sci 24:421-427. http://dx.doi.org/10.1016/S0165-6147(03)001779.

Zorrilla EP, Logrip ML, Koob GF (2014) Corticotropin releasing factor: a key role in the neurobiology of addiction. Front Neuroendocrinol 35:234-244. http://dx.doi.org/10.1016/j.yfrne.2014.01.001. 